\title{
Histochemical Studies on Epithelial Lipid in the Gallbladder of the Mouse
}

\author{
By \\ Kazuyori Yamada \\ Department of Anatomy, Nagoya University \\ School of Medicine, Nagoya, Japan \\ (Directors: Profs. Drs. Ch. Tog a ri and J. H a ra)

\section{Introduction}

Since a contribution by V i r c h ow (1857), numerous studies have appeared on epithelial lipid of gallbladder in various vertebrates (A s choff, '06; Shikinami, '08; Jurisch, '09; A sch of f and B a cmeister, '09; Policard, '14; Kusnetzowsky, '23; $\mathrm{N}$ a u n n, '23; Torinou mi, '24; H al pert, '27; Kat a ta, '28; Pf üh l, '32; Hosono, '35; Nagahiro, '38; Togari and Oka$\mathrm{d}$ a, '53; W all raff and Dietrich, '57 and $\mathrm{Yamada}$ ' 59). In these studies. however, few attempts have been made to elucidate the chemical composition of the lipid, excepting recent investigations carried out from the histochemical view-points (Wall raff and Dietrich, and Y a mada).

Therefore, further histochemical studies on epithelial lipid of gallbladder in each animal species are significant in the light of comparative histology of the organ.

The investigations reported here, hence, concern mainly with histochemical analysis of epithelial lipid in the gallbladder of the mouse. As an article on the cytology and histology of the gallbladder epithelium of this animal ( $\mathrm{M} \circ \mathrm{ri}$, '38) was published from the author's laboratory, the results described therein were in some detail referred to.

\section{Material and Methods}

A total of seventy five mice of both sexes were sacrificed by chloroform anesthesia. After the gallbladders were removed from the hosts, they were immersed in physiological saline solution $(0.85 \%)$ 
to prevent epithelial injury due to the chemical action of bile. Some of the specimens thus prepared were immediately used as unfixed frozen sections for the digitonin test for free cholesterol and plasmal reaction (after $\mathrm{H}$ a y e $\mathrm{s}$, '49) for acetal phosphatides. Others were fixed in routine lipid-preserving solutions such as $10 \%$ neutral formalin, B a ke r's formol-calcium fixative and formol-saline mixture. Freezing technique was used to section these fixed tissues at thicknesses of 10 to $15 \mu$. Histochemical staining reactions employed were as follows; Sudan black B stain for lipids in general, nile blue procedure ( $\mathrm{C}$ a $1 \mathrm{n}$, ' 47 ) for acidic and nonacidic lipids, acid haematein method

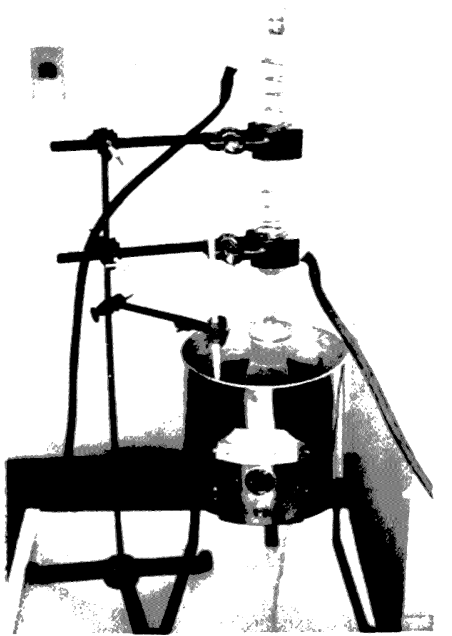

Simple apparatus for extraction (B a k e r, '46) for phospholipids, periodic acid-Schiff (PAS) reaction with prior treatment with dimedone (5:5-dimethylcyclo-hexane-1:3-dione) for PAS-reactive lipids, Schultz method (after R o mie u, '25) for cholesterol and its esters, Fis chler's method for fatty acids ard their insoluble soaps and finally performic acid-Schiff (PFAS) reaction ( $\mathrm{P}$ e a r s e. '54b) with a control by kromination ( $\mathrm{L}$ i $11 \mathrm{i}$ e, '52) for lipids containing unsaturated double bonds. Further, several extraction procedures controlling some of the results obtainable with the above methods were attempted. Among them are pyridine extraction prior to Sudan black B and acid haematein procedures and selective extractions (Modification of Ke ilig's ('44) original method) with cold acetone, hot acetone, hot ether and a hot mixture of equal parts of chloroform and methanol

\section{Observations}

The mucous epithelium of the mouse gallbladder is paved with a single layer of columnar cells, as a previous study from the author's laboratory (M or i. '38) indicated. The epithelial cells measure approximately 16 to $26 \mu$ long and 5 to $8 \mu$ wide. Their free surface is provided with a cuticular border which is structurally uniform. 
In the cytoplasm of most cells, there occurs lipid staining in a black shade by Sudan black B (Fig. 1). The lipid appears morphologically in two different figures. One type consists of exceedingly fine particles and the other of somewhat coarse particles of different sizes. The two types of lipid particles are distributed in the cytoplasm in a pattern varying with the individual cells. In some celts, they are localized predominantly at one site of the cytoplasm, while in others they are packed densely in the cytoplasm. There is, however, a general tendency for the fine particles to be diffusely scattered in the cytoplasm and for the coarse ones to be distributed mainly at the distal and basal regions of the cytoplasm. Lipid spheres of different sizes are occasionally found to cling to the free borders of cells which are loaded with lipid particles (Fig. 1).

When treated with nile blue, a pale red or blue shade develops generally in some of the two types of sudanophilic lipid particles. The blue shade appears chiefly in those particles located at the juxtanuclear and basal areas of the cytoplasm.

B a $k \in$ r's acid haematein stain produces a positive color of blueblack in a considerable number of the two types of particles, and among others in those visualized in the basal half. of the cell body (Fig. 2).

Some lipid particles react positively to the PAS-reagent employed. Fine particles are the main reactor, but some coarse particles are frequently stained purplish red. The PAS-reactive fine particles show predominantly distal and basal localizations. Their arrangement becomes, it seems, denser as one approaches the basal end of the cytoplasm (Fig. 3).

Negative $\mathrm{Schultz}$ reaction appears to be common to both types of lipid particles. In some cytoplam, however, a small amount of granular entities of different sizes are encountered mainly in the basal region. They are, on exposure to $\mathrm{Schultz}$ reagent, colored dark orange turning rapidly to feeble green in shade.

Careful examination of digitonin-treated epithelial cells with polarized light can not demonstrate with certainty the intracellular presence of genuine birefringent crystal.

If the Fischler's procedure is applied to the epithelium, no appreciable blackening takes place in the two types of sudanophilic lipid particles in the cytoplasm. In other terms, the epithelial lipid shows almost negative $\mathrm{F}$ is $\mathrm{ch}$ le r's reaction.

Among the two types of lipid particles, there occur some which yield positive plasmal reaction in a reddish purple shade. These 
plasmal positive particles are found mainly in both distal and basal cytoplasm, whereas they are seldom found in the paranuclear cytoplasm.

PFAS-reaction was employed to the epithelium examined here with the following results; a shade of pale reddish purple develops usually in some of the fine lipid particles and an intense reddish purple shade appears in some of the coarse particles (Fig. 4). These stainabilities of the two types of particles are mostly abolished by prior bromination of the tissue at room temperature for 1 hour (Fig. 5).

Every type of sudanophilic lipia particles in the epithelium is thoroughly extracted, if the sections are immersed in pyridine at $60^{\circ} \mathrm{C}$ for 24 hours (Fig. 6). Further, selective extractions with four lipid solvents yielded the following effects upon the epithelial lipid. First, extraction with cold acetone for 24 hours causes, as a rule, the extinction of some of the coarse lipid particles along with the loss of a small number of the fine particles (Fig. 7). The extinction of coarse particles is likely to occur primarily in the distal and parazuclear regions of the cytoplasm, while it is least in the basal cytoplasm. Further loss of some lipid particles is observable in the epithelial cells which are immersed in hot acetone for 24 hours after pretreatment with cold acetone (Fig. 8). In this type of extraction, diminution of both fine and coarse particles is recognizable generally in the distal and basal portions of the epithelial cytoplasm. Moreover, epithelium incubated in hot ether for 24 hours after prior immersion in cold acetone, is almost free from both fine and coarse lipid particles (Fig. 9). Finally, extraction with a hot mixture of equal parts of chloroform and methanol for 24 hours after prior treatment with cold acetone, makes the epithelial cells completely devoid of sudanophilic lipid particles (Fig. 10). Therefore, the effect of this extraction on the epithelium is approximately similar to that of the above treatment with hot ether.

\section{Discussion}

According to Mori's ('38) investigations, the gallbladder epithelium of the mouse is devoid of lipid. This information is somewhat inconsistent with the observations made by the present author. The incompatibility of the two results appears difficult to comprehend. However, discrepancies in the heredity of the mice, sudan 
dyes and staining procedures employed in the respective studies, are enumerated as possible factors involved. Further, it should be recognized that some lipids demonstrated here are such moieties as constituting cell organoids like mitochonỏria and $\mathrm{Gol} \mathrm{g} i$ apparatus in the cytoplasm.

The data of histochemical analysis obtained here, are logically interpretable, when raliable views of several histochemists (K e il i g, '44; Go mori, '52; Lis o n, '53; Pearse, '54a; Oka moto et al, '55; Araki and $\mathrm{Tong}$, '58 and $\mathrm{Casselman,} \mathrm{59)} \mathrm{are} \mathrm{referred}$ to. Epithelial lipid stainable with Sudan black B in the gallbladder of the mouse, consists primarily of neutral fats and phospholipids. Additionally, it contains some acetal phosphatides. Hence, this histochemical composition of the epithelial lipid resembles, to a great extent, that reported in the human gallbladder (Wall raff and D i e trich, '57). Further, it is likely that some of the lipids under discussion consist of such moieties as containing unsaturated double bonds like ethylene group $(\mathrm{CH}=\mathrm{CH})$. No accurate conclusion is drawn as to whether cholesterol and its esters exist in the lipid studied here. It appears, however, unsafe to establish definitely the absence of cholesterol and its esters, as realized from the occasional occurrence of spherical entities tinged dark orange by $\mathrm{Schultz}$ reagent in some cytoplasm. This result is coincident with that of the histochemical analysis of epithelial lipid in the human gallbladder (Wallraff and Dietrich, '57). However, it is in discordance with several observations indicating the occurrence in large quantities, of epithelial cholesterol in the gallbladder of different mammals (Policard, '14; Na n y n, '23 and $\mathrm{Katata,} \mathrm{'28).}$ Hence, further studies are needed in order to elucidate whether cholesterol and its esters are the constant moieties occurring abundantly in epithelial lipid of gallbladder in various mammals.

\section{Summary}

1. In the gallbladder epithelium of the mouse, there appears lipid staining in a black shade by Sudan black B. The substance occurs in the form of fine particles or somewhat coarse particls of different sizes.

2. A series of histochemical reactions and extraction tests employed here revealed the chemical composition of the lipid; neutral fats and phospholipids constitute the major components, while a 
certain type of acetal phosphatides is an additional moiety.

3. It is likely that some of sudanophilic lipids in the epithelium consist of such moieties as containing unsaturated double bonds.

4. Cholesterol and its esters are scarcely demonstrable by histochemical tests for them. Still, it seems unsafe to exclude their occurrence in the epithelium.

\section{Acknowledgments}

The author wishes to express his appreciation to Profs. Drs. Ch. $\mathrm{T}$ o g a ri and J. H a r a for their continued encouragement and suggestion during the course of the present study.

Thanks are also due to Mr. F. S a nd a for his technical assistance in preparing the photomicrographs in this manuscript.

\section{References}

A s ch of f, L.: Zur Frage der Cholesterinbildung in der Gallenblase. Münch. Med. Wsch., 38 : 1847-1848, 1906.

A s chof f, L. und B a cme is ter, A.: Die Cholelithiasis. Jena, 1909. (Cited from $\mathrm{P}$ f ü h l, '32).

A raki, M. and C.C. Tong: Histochemistry of lipids and vitamines A and D. Chemistry of lipids, 2: 166-182, Tokyo, 1958. (Japanese).

B a ker, J.R.: Quart. J. micr. Sci., $87: 441$, 1946. (Cited from Pe a r s e, '54a).

C a i n, A. J.: Quart. J. micr. Sci., $88: 383$, 1947. (Cited from Pe a r se, '54a).

C a s s $1 \mathrm{~m}$ a n, W. G. B.: Lipids. Histochemical technique, 64-90, London, 1959.

F i s c hle r, C.: Zbl. allg. Path. path. Anat., $15: 913$, 1904. (Cited from P e a r s e, '54a).

Gomori, G.: Lipids. Microscopic Histochemistry, Principles and Practice, 91-111, Chicago, 1952.

H a 1 pert, B.: Morphological studies on the gallbladder 1. A note on the development and the microscopic structure of the normal human gallbladder. Bull. Hopkins Hosp., $40: 1927$. (Cited from Y a m a d a, '59).

Hos ono, Sh.: Cultivation in vitro of the epithelium of gallbladder from guinea pig. III. Soc. path. jap., $25:$ 430-431, 1935.

H a y e s, E. R.: Stain technol., $24: 1949$. (Cited from Pear s e, '54a).

J u risch, A.: Beiträge zur mikroskopischen Anatomie und Histologie der Gallenblase. Anat. Hefte, 39 : 393-467, 1909.

$\mathrm{K}$ at at a, B.: Experimental studies on the behavior of gallbladder and bile duct epithelia in cholesterin excretion. Byori Kiyo, $5: 517-592,1928$. (Japanese).

Kusnetzowsky, N.: Ueber die Fettresorption und Ausscheidung durch das Epithel der Gallengänge. Mitt. Grenzgeb. Med. u. Chir., 37 : 145-162. 1924.

Keilig. I.: Ueber Spezifitätsbreite und Grundlagen der Markscheidenfärbungen (Nach Untersuchungen an fraktioniert extrahierten Gehirnen). Vir chow's Arch., 312: 405-420, 1944.

L i 11 i e, R. D.: Stain technol., $27: 37,1952$. (Cited from Pearse, '54a).

L is on, L.: Substances grasses. Histochimie et cytochimie animales principes et 
méthodes, 307-365, Paris, 1953. (Japanese).

Mori, Sh.: Histology and histogenesis of the gallbladder in the mouse. Nagoya Igakkai Z., 47 : 585-606, 1938. (Japanese).

$\mathrm{Nag}$ a h i r o, K.: Zytologische Untersuchungen über die Epithelzellen der Gallenblase des Menschen. Cytologia, 9 : 132-163, 1938.

N a u n y, B.: Weitere Beiträge zur Entstehung und Bau der Gallensteine. Mitt. Grenzgeb. Med. u. Chir., $36:$ 1-8, 1923.

$\mathrm{O}$ k a m o to, K., M. U e d a and R. M a d a : Lipids. Microscopic histochsmistry, 269312, Tokyo and Osaka, 1958. (Japanese).

Policard, A.: Recherches histochimiques sur les substances grasses, absorbeés au niveau de la vésicule biliaire. C. r. Soc. Biol., 76: 518-520, 1914.

Pfühl, W.: Die Gallenblase umd die extrahepatische Gallengänge. Mölle nd o.rf f's Handb. d. mikr. Anat. d. Mensch., 5 : 426-462, Berlin, 1932.

Pearse, A.G.E.: Lipids and lipoproteins. Histochemistry Theoretical and Applied, 165-189, London, 1954a.

: Appendices 8 and 9. Ibid., 441-445, London, 1954b.

R o m i e u, M. : C. R. Assoc. Anat., $20: 345$, Paris, 1925. (Cited from C a s s e $1 \mathrm{~m}$ a n, '59).

$\mathrm{Sh}$ ikinami, J.: Beiträge zur mikroskopischen Anatomie der Gallenblase. Anat. Hefte, 36 : 551-599, 1908.

Schultz, A.: Eine Methode des mikrochemischen Cholesterin Nachweises am Gewebeschnitt. Zbl. allg. Path. path. Anat., 35 : 314-317, 1924.

Togari, Ch. and T. Ok a d a: The minute structure of the epithelium of the human gallbladder. Okajimas Fol. anat. jap., $15:$ 1-12, 1953.

Tor in o u m i, K.: Woher stammt das Cholesterin der Gallensteine? Ziegler's Beitr., 72 : 456-474, 1924.

Virchow, R.: Ueber das Epithel der Gallenblase und über einen intermediären Stoff wechsel des Fettes. V i r ch ow's Arch., 11: 574-578. 1857.

W a $11 \mathrm{raff}$, J. und K.F. Dietrich: Zur Morphologie und Histochemie der Steingallenblase des Menschen. Z. Zellforsch., 46 : 155-231, 1957.

$\mathrm{Y}$ a $\mathrm{m}$ a d a, K. : The minute structure of the hamster gallbldder with special reference to the functions of the epithelium. Okajimas Fol. anat. jap., 33 : 321-351, 1959.

\section{Explanation of Figures}

1. Sudanophilic lipid in the gallbladder epithelium of the mouse. It appears in the form of fine or coarse particles in the epithelial cells. Neutral formalin: (Frozen section) Sudan black $B$, nuclei unstained. $\times 1300$.

2. Lipid particles demonstrated by $B$ a ke r's acid haematein stain in the epithelium. The blue-black coloration is intense in the particles situated at the basal half of the cell body. Formalin-calcium : (Frozen section) B a ke r's acid haematein stain, nuclei unstained. $\times 1300$.

3. PAS-stainability of lipid particles in the epithelium. The infranuclear distribution of fine particles showing positive reaction becomes denser as it approaches the basal end of the cytoplasm. Formalin-saline mixture: (Frozen section) Periodic acid-Schiff combined with prior treatment with dimedone, nuclei counterstained. $\times 1300$.

4. Epithelial cells stained with PFAS-reagent. Fine lipid particles react in a feeble positive shade, while coarse particles stain intensely. Neutral formalin: (Frozen 
section) Performic acid-S $\mathrm{ch}$ if $\mathrm{f}$, nuclei unstained. $\times 1300$.

5. PFAS-reactivity of lipid particles in the epithelium after immersion in bromine solution. The reactivities of the two types of particles are mostly abolished. Neutral formalin: (Frozen section) Performic acid-S $\mathrm{ch}$ if $\mathrm{f}$ combined with prior treatment with bromine solution, nuclei unstained. $\times 1300$.

6. Epithelium incubated in pyridine at $60^{\circ} \mathrm{C}$ for 24 hours and stained with Sudan black B. No lipid is detectable in the cytoplasm. A weak solution of B o u i n's fixative: (Frozen section) Sudan black B, nuclei unstained. $\times 1300$.

7. Epithelium immersed in cold acetone for 24 hours and stained with Sudan black B. Some coarse lipid particles and a few of fine particles are extracted from the cytoplasm, when compared with fig. 1. Cold acetone: (Frozen section) Sudan black $B$, nuclei unstained. $\times 1300$.

8. Epithelium immersed in hot acetone for 24 nours after pretreatment with cold acetone and stained with Sudan black B. Further loss of some lipid particles is observable in the cytoplasm. Cold acetone: (Frozen section) Sudan black B, nuclei counter-stained. $\times 1300$.

9. Epithelium immersed in hot ether for 24 hours: after pretreatment with cold acetone and stained with Sudan black B. Lipid particles are scarcely seen in the cytoplasm. Cold acetone: (Frozen section) Sudan black B, nuclei counter-stained. $\times 1300$.

10. Epithelium immersed in a hot mixture of equal parts of chloroform and methanol for 24 hours after pretreatment with cold acetone and stained with Sudan black B. The epithelial cells are found to be completely devoid of lipid particles. Cold acetone: (Frozen section) Sudan black B, nuclei counter-stained. $\times 1300$. 
Plate
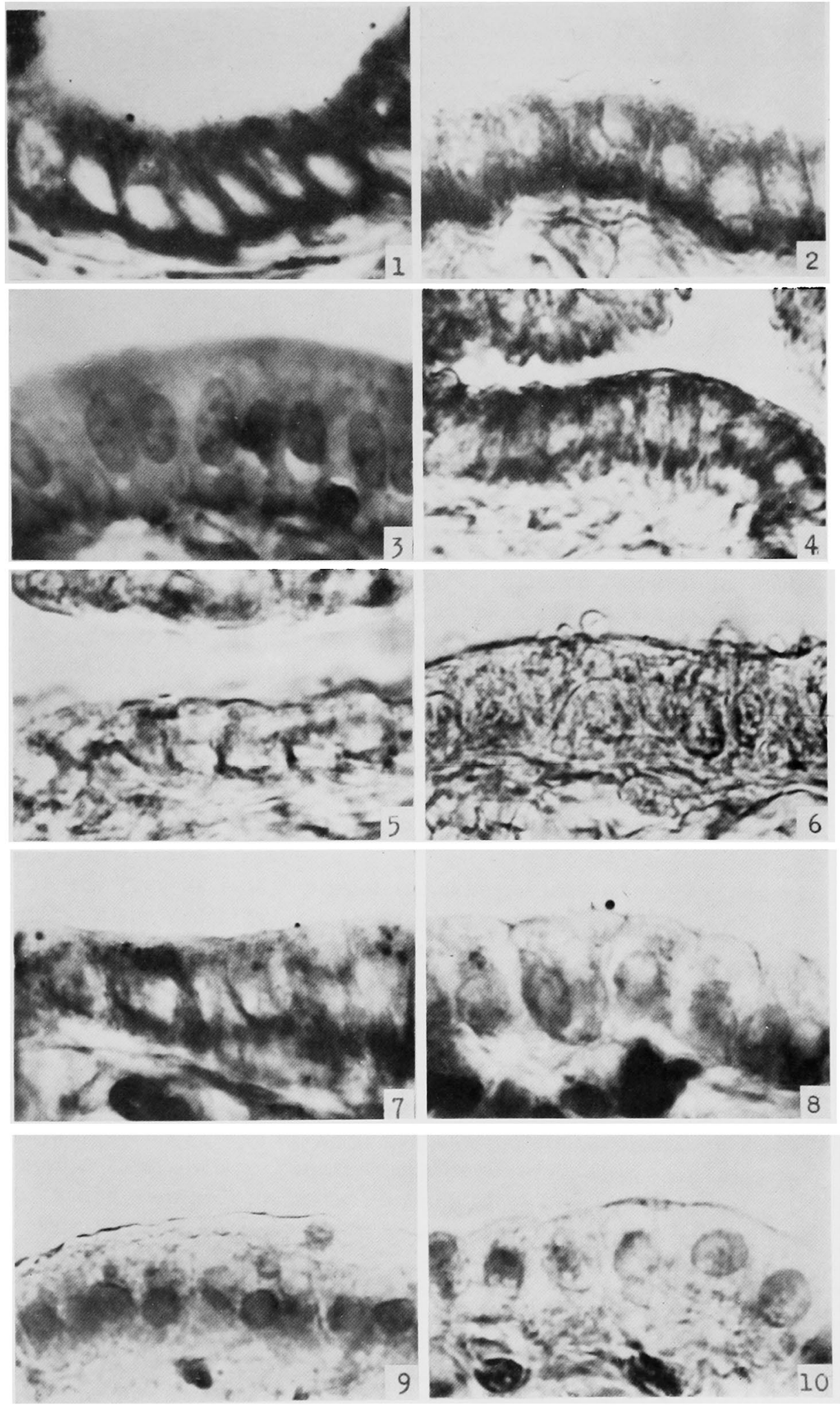

K. Yamada 